\title{
Advanced radar-interpretation of InSAR time series for mapping and characterization of geological processes
}

\author{
F. Cigna ${ }^{1}$, C. Del Ventisette ${ }^{1}$, V. Liguori ${ }^{2}$, and N. Casagli ${ }^{1}$ \\ ${ }^{1}$ Department of Earth Sciences, University of Firenze, Via La Pira 4, 50121 Firenze, Italy \\ ${ }^{2}$ Department of Civil and Environmental Engineering, University of Palermo, Viale delle Scienze, 90128 Palermo, Italy
}

Received: 26 October 2010 - Revised: 7 January 2011 - Accepted: 4 February 2011 - Published: 16 March 2011

\begin{abstract}
We present a new post-processing methodology for the analysis of InSAR (Synthetic Aperture Radar Interferometry) multi-temporal measures, based on the temporal under-sampling of displacement time series, the identification of potential changes occurring during the monitoring period and, eventually, the classification of different deformation behaviours. The potentials of this approach for the analysis of geological processes were tested on the case study of Naro (Italy), specifically selected due to its geological setting and related ground instability of unknown causes that occurred in February 2005. The time series analysis of past (ERS1/2 descending data; 1992-2000) and current (RADARSAT-1 ascending data; 2003-2007) ground movements highlighted significant displacement rates (up to $6 \mathrm{~mm} \mathrm{yr}^{-1}$ ) in 2003-2007, followed by a post-event stabilization. The deformational behaviours of instable areas involved in the 2005 event were also detected, clarifying typology and kinematics of ground instability. The urban sectors affected and unaffected by the event were finally mapped, consequently re-defining and enlarging the influenced area previously detected by field observations. Through the integration of InSAR data and conventional field surveys (i.e. geological, geomorphologic and geostructural campaigns), the causes of instability were finally attributed to tectonics.
\end{abstract}

\section{Introduction}

High frequency of geological processes (e.g. landslides, subsidence, earthquakes, tectonic motions, floods, volcanic activity and coastal erosion) and their consequences on

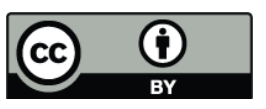

Correspondence to: F. Cigna (francesca.cigna@unifi.it) population, settlements, infrastructures and environment, highlight the need of a proper risk management and adequate urban planning to reduce impacts and damages on the elements at risk.

Management of natural hazards should be focused not only on emergencies, but also on forecasting and preventing the risks due to the potential occurrence of such phenomena, in order to pre-emptively develop detailed scenarios for emergency management and planning. Geological risk management needs therefore to be supported by a method or a technique that allows, quickly and at a low-cost, acquisition and monitoring of ground deformation and creation of hazard and risk maps. The measurement of ground displacements induced by geological phenomena often represents the most effective method to define the behaviour of a phenomenon and to assess the associated hazard and risk, supporting decision-making for risk reduction and the evaluation of short- and long-term effectiveness of planned mitigation measures.

Conventional methods for monitoring land deformation (e.g. geodetic levelling and GPS - Global Positioning System) can be supported and integrated by optical and radar satellite remote sensing, benefiting from its multi-temporal resolution, wide area coverage and a significant reduction in field work and cost. Since the late 1990s, several approaches have been developed for processing satellite radar data, such as the standard InSAR (Synthetic Aperture Radar Interferometry) approach (Massonnet and Feigl, 1998; Rosen et al., 2000), which has been successfully used in the last years to measure ground deformation associated with geological processes, both at local and regional scale, using space-borne radar images (e.g., Goldstein et al., 1993; Massonnet et al., 1994; Fruneau et al., 1996; Singhroy et al., 1998; Kimura and Yamaguchi, 2000). The limits of the conventional InSAR two-image configuration (single-interferogram), such as temporal and geometric decorrelation and atmospheric phase

Published by Copernicus Publications on behalf of the European Geosciences Union. 
delay, have been recently overcome by multi-interferogram approaches, among which the PSI - Persistent Scatterer Interferometry (e.g., Costantini et al., 2000; Ferretti et al., 2001; Werner et al., 2003; Hooper et al., 2004) and the interferogram stacking (e.g., Berardino et al., 2002; Mora et al., 2003) approaches. The algorithms employed by these techniques take advantage of long temporal series of SAR data (e.g. ERS1/2, ENVISAT, RADARSAT1/2 images) to identify radar targets which are used to detect and measure ground displacements along the LOS (Line Of Sight) direction and to reconstruct the deformation history of the investigated area. Unlike the conventional interferometric approach, these techniques increase measurement accuracy from centimetre to millimetre through a better estimation of topography and atmospheric phases, providing a whole description of the temporal behaviour of the deformational field (time series analysis) and consequently solving the temporal variability of deformation (Crosetto et al., 2005).

In recent years, many applications have demonstrated the capabilities of these advanced approaches to detect slow land surface deformation (up to several $\mathrm{cm} \mathrm{yr}^{-1}$ ) and to understand the spatial distribution and temporal evolution of displacements. These analyses concern built-up areas affected by slow or very slow landslides (e.g., Hilley et al., 2004; Bovenga et al., 2006; Colesanti and Wasowski, 2006; Farina et al., 2006, 2008; Herrera et al., 2009; Greif and Vlcko, 2011), tectonic motions (e.g., Colesanti et al., 2003; Musson et al., 2004; Bürgmann et al., 2006; Vilardo et al., 2009), land subsidence (e.g., Canuti et al., 2005; Teatini et al., 2005; Dixon et al., 2006; Browitt et al., 2007; Stramondo et al., 2008; Osmanoglu et al., 2011), as well as volcanic activity (e.g., Lanari et al., 2004; Salvi et al., 2004; Tizzani et al., 2007).

This paper illustrates the capabilities of multi-pass InSAR measures for detection and mapping of ground deformation induced by geological processes. In particular, we describe and discuss a new post-processing approach for the analysis and interpretation of PSI time series and the consequent maximization of the number and usefulness of information extractable from multi-pass interferometric measures. This methodology is presented through the case study of Naro (Italy), specifically selected due to its peculiar geological setting prone to ground instability phenomena, the last of which occurred on 4 February 2005. This event particularly encouraged the implementation of the new approach as an operational tool to support emergency management activities.

\section{Methodology}

\subsection{InSAR "radar-interpretation" and "back monitoring" approaches}

Due to the intrinsic characteristics of multi-pass InSAR techniques (e.g., the ability to detect only the LOS component of ground movement and the point-wise spatial distribution of measures), the interpretation of radar data requires support from analysis and integration with thematic maps (i.e. topographic, geomorphologic, geological and land use maps), optical images (both aerial and satellite data) and in situ data (e.g. GPS data, levelling measures, etc.). Thus, InSAR and conventional techniques for the investigation of geological processes are combined through "radar-interpretation", to obtain an accurate analysis of the phenomenon at hand, for both its cognitive frame (i.e. typology, spatial extension, causes) and its temporal evolution. Although this approach has already been used for many years by the scientific community, the term "radar-interpretation" has been introduced by Farina et al. (2008) in the framework of landslide investigations and its definition and meaning are here extended to the wider class of ground deformation related to geological hazards.

Radar-interpretation can support different civil protection activities for the management of geological risks during all its phases (i.e. pre-disaster, response and post-disaster): (i) detection and inventory of mass movements; (ii) rapid mapping of hazard and damages; (iii) 'back monitoring' of ground deformation; (iv) spatial characterization (e.g. landslide boundary, extension and distribution); (v) assessment of residual hazard (i.e. evaluation of remaining hazard after a deformational event and/or the execution of countermeasures). In particular, "back monitoring" is here defined as "the measurement in retrospect of past deformation time series performed through the analysis of SAR archived data", and it translates in terms of operative effectiveness, the crucial concept of temporal reconstruction of past events. In Italy, this capability has been recently demonstrated by innovative and advanced analyses promoted and carried out by national and regional civil protection authorities in collaboration with scientific support centres, such as the Geohazards Research Lab of the Earth Sciences Department, University of Firenze (e.g., Canuti et al., 2005; Corsini et al., 2006; Farina et al., 2008; Casagli et al., 2009; Cigna et al., 2010b).

Depending on the objective of the analysis and on its spatial and temporal scale (e.g. hazard mapping over wide regions, displacement monitoring at local scale), "radar-interpretation" allows obtaining different information and includes different steps (Farina et al., 2008). The analysis of conventional InSAR data or PS (Persistent Scatterers) mean deformation rates is generally used for the detection and mapping of mass movements at large scale (e.g. updating of landslides inventory maps; Pancioli 
et al., 2008; Righini et al., 2008; Cigna et al., 2010a). It is also used for the evaluation of their state of activity and intensity and, finally, the hazard assessment (risk can also be evaluated if data about elements at risk are available). On the other hand, analysis focused on PSI deformation time series - associated to their average trends - is more appropriate for applications at local scale and to highlight any anomaly and/or acceleration that potentially occurred during the monitoring period. The detailed time series analysis and the "back monitoring" of past ground deformation provide also an essential contribution to the spatial and temporal characterization of geological hazards, the evaluation of their behaviour, their typology and their causes. These capabilities are necessary and essential for those phenomena that are not known a priori or not anticipated by precursor movements: since they are not usually kept under pre-planned surveillance before the catastrophic event, it is impossible otherwise to know their past stability conditions. After the occurrence of ground deformation and the consequent activation of an emergency, the analysis of radar images acquired in the past and immediately after the deformational event supports the post-event hazard assessment and recognition of potential residual deformation, and also the post-emergency identification of stable areas devoted to the potential relocation of the elements at risk (e.g., Corsini et al., 2006; Farina et al., 2008; Cigna et al., 2010b).

\subsection{Post-processing interpretation of PSI time series}

As discussed in the previous section, the analysis of PSI deformation time series is useful to highlight any potential anomaly and/or acceleration occurred during the monitoring period. In general, this capability is limited and driven by the phase model for deformation components chosen during the PSI processing to unwrap the interferometric phases and, secondarily, by the potential aliasing of PSI measures.

Usually, most of the multi-pass approaches use a simple linear function of phase variation through time to model ground motions (Ferretti et al., 2001; Colesanti et al., 2003; Werner et al., 2003; Crosetto et al., 2005). However, geological processes often cannot be described by such a trend. Rather, they need to be modelled with much more complex and non-linear functions (e.g. hyperbolic, seasonal, combined, etc.). For instance, non-linear components of land subsidence, which depend on the stage of soil consolidation, are well represented by hyperbolic models (Kim et al., 2010). Thus, the use of linear models during the processing sometimes leads to the underestimation and/or misunderstanding of the real deformation patterns of the investigated geological process, the ascription of the non-linear ground deformation components to other phase terms (e.g. the Atmospheric Phase Screen, APS) or even the exclusion of some points from the PS candidates and/or potentials (Ferretti et al., 2000). This issue occurs when the deformational behaviour of the analyzed PS is too different (i.e. too strong variation or acceleration) with respect to the deformation function (i.e. linear model). However, even if a simple linear model is chosen during the processing, sometimes it is possible to detect some non-linear signals inside the PS time series, as long as these signals do not compromise the phase coherence (i.e. decrease its value below a given threshold) of the radar targets and cause their exclusion from the subsequent processing steps.

PSI measures are also extremely vulnerable to phasealiasing effects, due to their ambiguous nature caused by the $2 \pi$ phase-wrapping. If no prior information on ground deformation is available, phase unwrapping problems may limit to a quarter of the wavelength, $\lambda / 4$ (e.g. $14 \mathrm{~mm}$ for C-band sensors, such as ERS, ENVISAT, RADARSAT), the maximum displacement between two successive acquisitions and two close PS of the same dataset (Ferretti et al., 2000, 2005; Hanssen, 2005; Raucoules et al., 2009; Crosetto et al., 2010). Depending on the spatial pattern of ground displacements (with respect to PS density) and their velocity (with respect to the temporal SAR sampling), some deformational phenomena cannot be detected or they are often underestimated (phase unwrapping errors).

Bearing these limitations of PSI data in mind and assuming that they do not compromise the result of the analysis, some post-processing approaches can be used on PSI time series to better analyze and understand the temporal and spatial patterns and characteristics of the investigated area.

From a geological point of view, non-linear behaviours can take place as a consequence of: (i) the nature itself of the deformation phenomenon (e.g. subsidence processes due to compaction generally show quadratic trends); (ii) a slow change in the predisposing or triggering factors (e.g. for landslide processes, heavy or prolonged rainfalls, water level changes, loading due to new constructions, urban excavations); (iii) the occurrence of a rapid deformation event (e.g. reactivation, seismic event).

One of these possible post-processing approaches to analyze in detail PS time series consists in under-sampling their time interval into different sub-samples in order to observe the potential changes in the deformational trend registered during the monitoring period. Operatively, this approach starts with the division of the whole monitoring period in $n$ different sub-samples, i.e. $\left(t_{0}-t_{1}\right),\left(t_{1}-t_{2}\right)$, $\ldots\left(t_{n-1}-t_{n}\right)$, and then the calculation of new mean deformation rates (i.e. $v_{1}, v_{2}, \ldots v_{n}$ ) for each one of them, using a simple linear regression on ground deformation data, schematically shown in Fig. 1. These sub-samples are generally characterized by different time lengths and different numbers of averaged acquisitions, which strongly influence the accuracy and reliability of the recalculated deformation rates. Consequently, the simple numerical comparison of these sub-sampled displacement rates is usually not appropriate, unless it is done taking into account 


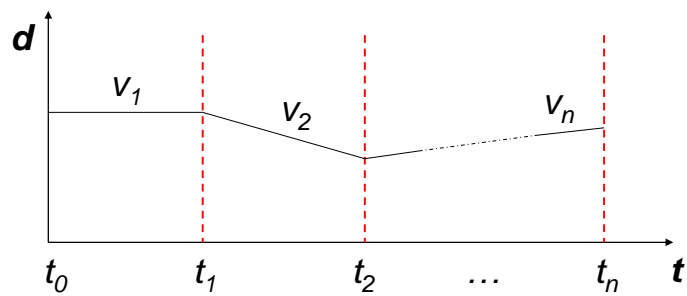

Fig. 1. Sub-sampling of PSI time series in $n$ different time intervals, i.e. $\left(t_{0}-t_{1}\right),\left(t_{1}-t_{2}\right),\left(t_{n-1}-t_{n}\right)$. The average deformation rates for each subsample, i.e. $v_{1}, v_{2}, v_{n}$, are recalculated as simple linear regressions on ground deformation data $(d)$.

the different variability of the deformation data with respect to the recalculated average rates, which depend on the number and distribution of the acquisitions of each time subsample. For instance, a suitable solution to parameterize the velocity deviations of different time frames could be the ratio between the difference of the recalculated rates, i.e. $\left(v_{n}-v_{n-1}\right)$, and the absolute value of the differences between their respective sums of squared residuals from the recalculated rates, i.e. $\left|r s s_{n}-r s s_{n-1}\right|$. Such a parameter not only evaluates the magnitude of the deformation velocity changes, but also identifies their different polarization, i.e. accelerated or decelerated patterns (depending on both the plus or minus sign of the numerator, i.e. $v_{n}-v_{n-1}$, and the sign of the LOS velocities, i.e. toward or away from the satellite).

When the occurrence of a deformational event due to geological processes or human actions causes a local alteration of the expected trend of PS time series, it is possible to perform a classification based on the response of each PS to the deformational event, discriminating the targets affected and unaffected by ground displacements. Unlike the first approach, this second one does not compare the deformation rates of the radar targets numerically, but it is rather based on the "labelling" (i.e. classification) of each displacement time series. Operatively, a simple approach to classify the deformational patterns can be used, defining two main categories of radar targets with respect to an event, and identifying them inside the available PS dataset (Fig. 2):

- "Unaffected targets": points whose time series are not influenced by the event. These targets are stable (S) or characterized by linear deformation trend (L), away or toward the satellite.

- "Affected targets": points whose time series are influenced by the event. These targets undergo either a temporary $(\mathrm{T})$ or a permanent $(\mathrm{P})$ change (e.g. acceleration, rapid displacement, etc.) in their trend.

The case study of Naro represents the first application of the above-described approach.
UNAFFECTED TARGETS

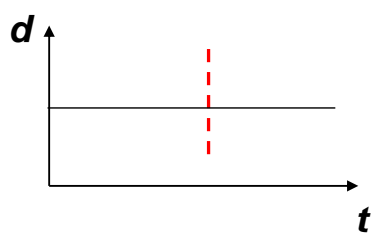

Stability $(S)$

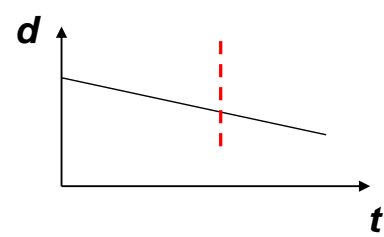

Linear trend $(L)$

\section{AFFECTED TARGETS}

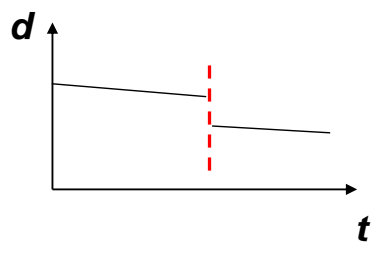

Temporary change $(T)$

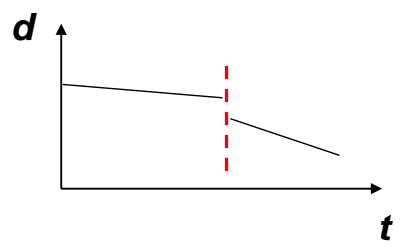

Permanent Change $(P)$
Fig. 2. Classification of PSI time series with respect to a deformational event (red dashed line). Two different deformational behaviours ( $d$, displacements; $t$, time) are identified: unaffected targets (classes S and L) and affected targets (classes T and P).

\section{Naro (Italy)}

\subsection{Geological and historical background}

The town of Naro is located in the province of Agrigento, in southern Sicily, Italy (Fig. 3), and it was one of the most important Sicilian urban centres of the Middle Ages. It has an administrative area of about $207 \mathrm{~km}^{2}$ and, currently, a total population of about 8500 inhabitants.

The Naro municipality is located at the edge of the Apennine-Maghrebian thrust belt, on the Plio-Pleistocene and Miocene sediments of the Gela Nappe, and its geological setting is connected with a geodynamic evolution dating back to the regressive phase of Caltanissetta basin (Grasso and La Manna, 1990; Grasso et al., 1995; Lickorish et al., 1999; Lentini et al., 2006; Ghisetti et al., 2009). The urban area is built on the southwestern side of a hill on which Upper Pliocene calcarenite and sand sediments, overlaying with continuity of sedimentation Middle Pliocene clay sediments, crop out (Regio Ufficio Geologico, 1885). As revealed by geological field surveys, the calcarenite layers dip to the SW with an average slope of $20^{\circ}$, have a variable thickness (proceeding from NW to SE, from less than $10 \mathrm{~m}$ up to $40 \mathrm{~m}$ ) and many sub-vertical discontinuities. They are characterized by brittle rheological behaviour and are not homogeneous and compact but have high porosity and intercalations of sandy silt. Clays are characterized by less 


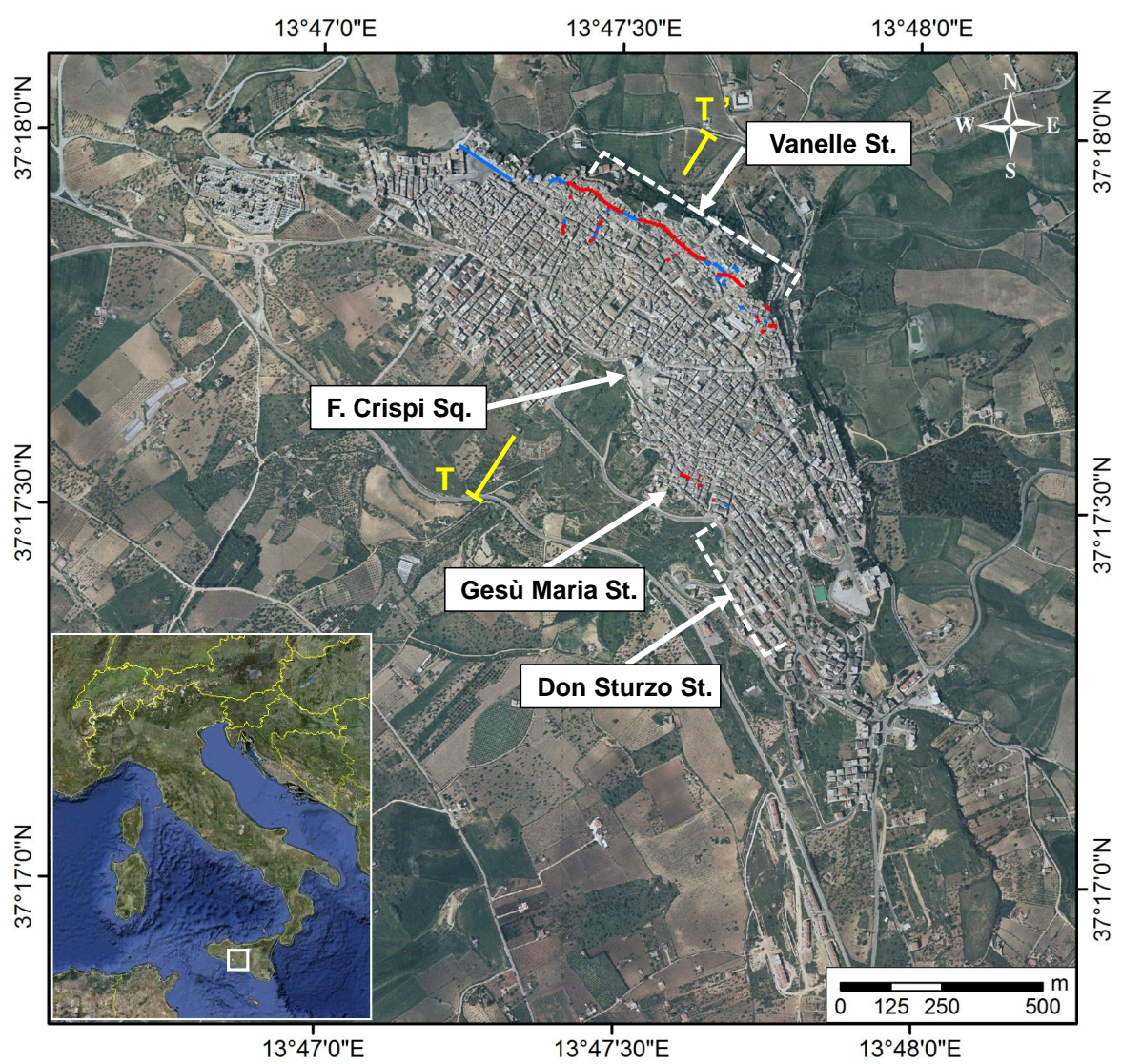

Fig. 3. Location map (inset, Google Earth 2010) and overview of the town of Naro (Italy). The most damaged buildings (event of 4 February 2005) are located in the areas of Vanelle St. (historic area) and Gesù Maria St. (southeastern area). Fractures with millimetre (blue lines) and centimetre (red lines) aperture were mapped by the Regional Civil Protection Department (DRPC). T- $\mathrm{T}^{\prime}$ cross section (yellow line) is shown in Fig. 15.

developed and pervasive fractures instead and have a plastic rheological behaviour.

The southwestern side of the hill on which the town has developed has an elevation of 460-593 $\mathrm{m}$ a.s.l. with a slope of $12-14^{\circ}$ and shows some well-marked slope changes and morphologic steps and scarps of probable morpho-tectonic origin, such as a main scarp located immediately south of F. Crispi Sq., in the central sector of the urban area (Fig. 3). The northeastern side of the hill is steeper (sub-vertical) and in this sector the stratigraphic contact of Upper Pliocene calcarenite and underlying Middle Pliocene clays crops out. The origin of the morpho-tectonic scarps on the southwestern side of the hill is reasonably connected to the geodynamic evolution of the Gela Nappe and to its southward motion, inducing E-W and SE-NW faulting and fracturing in the whole Caltanissetta basin (Grasso and La Manna, 1990; Grasso et al., 1995; Lickorish et al., 1999). According to this morphologic setting and the presence of many steps and slope changes in the calcarenite and sand sediments of Naro, urban structures and road network were built and developed along two main directions: SE-NW (such as Vanelle St., Fig. 3) and SW-NE.
On 4 February 2005 Naro was affected by ground instability, which caused the opening and the reactivation of many fractures (previous documented occurrences date back to $1679,1816,1834,1908,1934,1940,1942$ and 1997) in the buildings and along the streets within the northeastern and southeastern sectors of the town (Fig. 4). Following the development of these severe damages, the Regional Civil Protection Department (hereafter DRPC) activated the emergency plan and mitigation measures in order to reduce impacts on the elements at risk.

Thanks to some structural field surveys carried out after 4 February 2005 by the DRPC, it was highlighted that the most affected sectors of the town were the historic area (with major damages especially on the buildings located N of Vanelle St.) and the southeastern area (Gesù Maria St. and Don Sturzo St., showing less severe damages; Fig. 3). The fracture aperture on the buildings and on the road surface of the urban area was from a few millimetres up to $1-2 \mathrm{~cm}$. Their dip was sub-vertical or tilted to $\mathrm{SW}$ of about $45^{\circ}$ from the vertical direction (Fig. 4).

Despite the poor construction quality of the buildings in these areas, the fractures showed the existence of a 

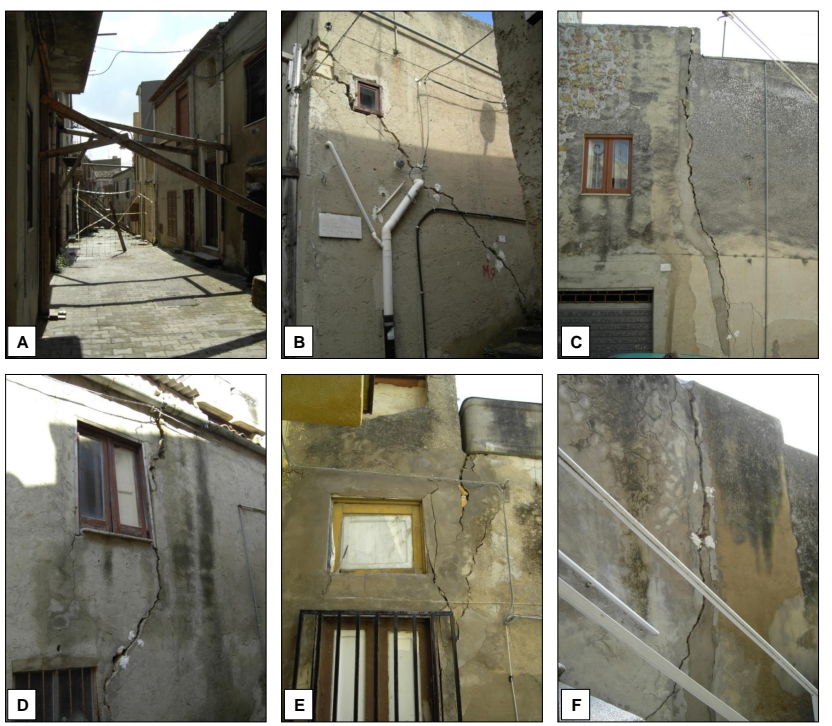

Fig. 4. Overview of Vanelle St. in Naro (A) and examples of centimetre fractures in the buildings located on its northern side (B-F). These structural damages are connected with ground and structural instability that occurred on 4 February 2005 (photos taken on 5 April 2007).

A
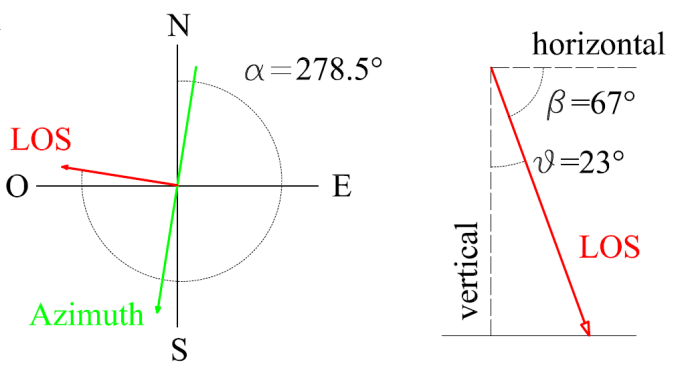

$\mathbf{B}$
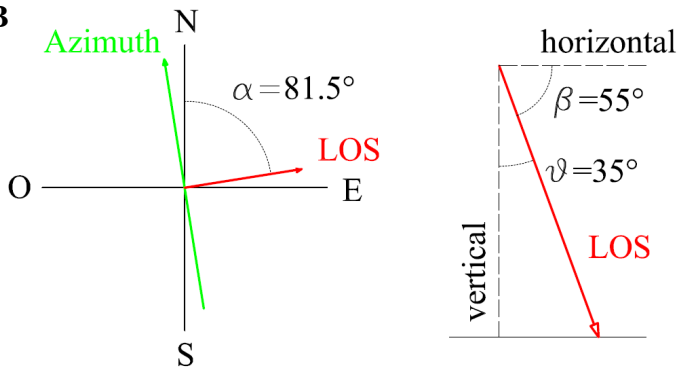

Fig. 5. Line Of Sight (LOS; red vector) geometrical characteristics for ERS1/2 in descending mode (A) and RADARSAT-1 (Standard Beam Mode 3) in ascending mode (B). $\alpha$, azimuth; $\theta$, look angle (measured between LOS and vertical direction); $\beta$, tilt (measured between LOS and horizontal direction); green vector, azimuth direction. significant stress distributed along the NNW-SSE direction, both in the upper (Vanelle St.) and lower (Gesù Maria St.) part of the town, but not necessarily related to the same dynamics (Fig. 3). The nature of these phenomena was long debated. Since 2005, several different hypotheses (e.g. rotational landslide of calcarenite layers toward the SW, lateral spread toward the NE, local subsidence due to collapse of subsurface cavities) were proposed by the DRPC and also by the Regional Department for the Environment and Land Protection during the drawing up of the Hydrogeological Setting Plan (PAI - Piano di Assetto Idrogeologico) of Naro river basin in 2006. Some of these hypotheses turned out to be improbable, thanks to the results of the geological, geomorphologic and geostructural field surveys carried out in 2006. Additionally, the outcomes from the interferometric analysis, described in the following subsections, were also fundamental for the interpretation of the 2005 event.

\subsection{SAR data and PSI analysis}

66 ESA (European Space Agency) ERS1/2 images acquired along descending orbits and 54 CSA (Canadian Space Agency) RADARSAT-1 images acquired along ascending orbits, were used to perform the interferometric analysis. ERS images span the time interval between 11 November 1992 and 23 December 2000 and have a nominal revisiting time (temporal resolution) of 35 days (each satellite), whereas RADARSAT data span the time interval between 21 March 2003 and 11 May 2007 with a nominal revisiting time of 24 days (Table 1). With regard to ERS data, we opted for SAR images acquired along descending orbits to exploit their actual good temporal coverage in the Italian territory, considering also the very low frequency of ascending acquisitions. To study current ground displacements we preferred to use RADARSAT instead of ENVISAT data in order to exploit their shorter revisiting time (24 days) and to get higher accuracy and better spatial density of measures. Ascending orbits were selected for the RADARSAT analysis to compare their potentials for the study of land displacements occurred in the NE sector of the town, with respect to the ERS descending data.

LOS of ERS satellite in descending mode and RADARSAT satellite (Standard Beam mode 3 ) in ascending mode are characterized by azimuth $(\alpha)$ and look angle $(\theta)$, respectively, $\alpha=278.5^{\circ}$ and $\theta=23^{\circ}, \alpha=81.5^{\circ}$ and $\theta=35^{\circ}$ (Fig. 5). Both satellites use a C-band radar signal, with wavelength $\lambda=5.6 \mathrm{~cm}$ and frequency $f=5.3 \mathrm{GHz}$ (Table 1).

The two SAR data stacks, ERS1/2 and RADARSAT-1, were separately processed by TeleRilevamento Europa (TRE) with the PSInSAR (Permanent Scatterers InSAR) technique, a PSI approach developed in 1999 by the Polytechnic University of Milan, Italy (Ferretti et al., 2001). According to the standard processing of this technique, a simple linear model of phase variation through time was 
Table 1. Main characteristics of ERS and RSAT-S3 (RADARSAT-1 in Standard Beam Mode 3) PS-InSAR analyses for the town of Naro. Mean PS density is relative to the whole analyzed area (about $35 \mathrm{~km}^{2}$ ), while maximum density is calculated for the inner urban area. $\lambda$, signal wavelength; $f$, signal frequency; $\theta$, look angle - measured between the LOS and the vertical direction; $\alpha$, azimuth - measured between the $\mathrm{N}$ direction and the LOS; Desc, descending; Asc, ascending.

\begin{tabular}{|c|c|c|c|c|c|c|c|c|c|c|}
\hline & \multicolumn{6}{|c|}{ Satellite characteristics } & \multicolumn{4}{|c|}{ PS-InSAR analysis } \\
\hline Data stack & $\lambda[\mathrm{cm}]$ & $f[\mathrm{GHz}]$ & Orbit & $\theta\left[{ }^{\circ}\right]$ & $\alpha\left[^{\circ}\right]$ & $\begin{array}{l}\text { Nominal revisiting } \\
\text { time [days] }\end{array}$ & $\begin{array}{l}\text { Time } \\
\text { interval }\end{array}$ & $\begin{array}{l}\text { Identified } \\
\text { PS }\end{array}$ & $\begin{array}{l}\text { Mean PS } \\
\text { density } \\
{\left[\text { PS km }^{-2}\right]}\end{array}$ & $\begin{array}{l}\text { Maximum } \\
\text { PS density } \\
{\left[\mathrm{PS} \mathrm{km}^{-2}\right]}\end{array}$ \\
\hline ERS & 5.6 & 5.3 & Desc & 23 & 278.5 & 35 (each sat.) & $\begin{array}{l}11 / 11 / 92- \\
23 / 12 / 00\end{array}$ & 1570 & 45 & 1484 \\
\hline RSAT-S3 & 5.6 & 5.3 & Asc & 35 & 81.5 & 24 & $\begin{array}{l}21 / 03 / 03- \\
11 / 05 / 07\end{array}$ & 2587 & 74 & 1417 \\
\hline
\end{tabular}

selected for the estimation of phase components related to land deformation. The Digital Elevation Model (DEM) used during the processing is the SRTM (Shuttle Radar Topography Mission) with a resolution of $1.454 \cdot 10^{-5} \mathrm{rad}$ (approximately $90 \mathrm{~m}$ ), produced by NASA. The location of the reference points for ERS and RADARSAT analyses were chosen inside two areas assumed to be devoid of ground displacements due to their geological and geomorphologic properties and also taking into account the distribution of phase coherence in the two different data stacks (geographic coordinates for ERS reference point: $13^{\circ} 39^{\prime} 55^{\prime \prime} \mathrm{E}, 37^{\circ} 19^{\prime} 25^{\prime \prime} \mathrm{N}$; RADARSAT reference point: $13^{\circ} 46^{\prime} 55^{\prime \prime} \mathrm{E}, 37^{\circ} 17^{\prime} 52^{\prime \prime} \mathrm{N}$; Fig. 7). From the geological and geomorphological point of view, these reference targets are located on calcarenite and sand sediments, presumably not affected by local scale deformation processes. On the other hand, the presence of active regional tectonics in this area cannot be ruled out; nevertheless, a potential tectonic contribution at large scale would not compromise the applicability and reliability of the PSI data interpretation at local scale.

\subsection{PSI "back monitoring" and "radar-interpretation"}

The PSInSAR processing allowed the identification of more than 1500 Permanent Scatterers (PS) in the time interval 1992-2000 (ERS data) and more than 2500 PS in 2003-2007 (RADARSAT data), over the urban and peri-urban areas (Figs. 6, 7 and Table 1). Mean PS densities (relative to the whole analyzed area) were $45 \mathrm{PS} \mathrm{km}^{-2}$ for ERS1/2 data and $74 \mathrm{PS} \mathrm{km}^{-2}$ for RADARSAT-1 data, while maximum PS densities (calculated for the inner urban area) were $1484 \mathrm{PS} \mathrm{km}^{-2}$ and $1417 \mathrm{PS} \mathrm{km}^{-2}$, respectively (Table 1).

\subsubsection{Ground deformation rates}

PS ground deformation measures highlighted the general stability of the town between 1992 and 2000 (Fig. 6).
Any obvious correlation between the presence of significant deformation rates and the fractures in the historic or in the southeastern area of the town was not detected. Moreover, only a few radar targets measured a LOS deformation rate higher than $1.5 \mathrm{~mm} \mathrm{yr}^{-1}$ and generally lower than $3 \mathrm{~mm} \mathrm{yr}^{-1}$, in the direction away from the satellite (positive and negative PS deformation values in Fig. 6 indicate, respectively, movements toward and away from the satellite). On the contrary, the InSAR analysis highlighted significant deformation rates between 2003 and 2007, both in the historic and in the southeastern part of the town (Fig. 7). In the area of Vanelle St., the mean deformation rates ranged from 2 up to $6 \mathrm{~mm} \mathrm{yr}^{-1}$ away from the sensor and, in the eastern sector of the town, the rates were about $3-4 \mathrm{~mm} \mathrm{yr}^{-1}$.

Considering ERS and RADARSAT LOS orientation and the geometry of ground deformation (revealed by conventional field surveys), LOS ground deformation measured with the interferometric analysis represents only a small fraction of the displacements that actually occurred in the urban area of Naro. This topic is discussed in detail in the following subsection.

\subsubsection{Time series analysis}

Radar-interpretation at local scale includes the analysis of deformation time series in order to highlight any acceleration and/or anomalous motion that potentially occurred during the monitoring period. An InSAR time series analysis was therefore carried out for Naro to detect the areas affected by ground deformation, to identify the presence of potentially precursor movements and to evaluate changes in deformation rates connected with the reactivations of November 1997 and February 2005.

The 1997 reactivation was not evidently detectable inside the 1992-2000 time series. However, the observation of RADARSAT (2003-2007) PS time series highlighted that many radar targets, located not only downstream of Vanelle St. but also in the central area of the town, registered 


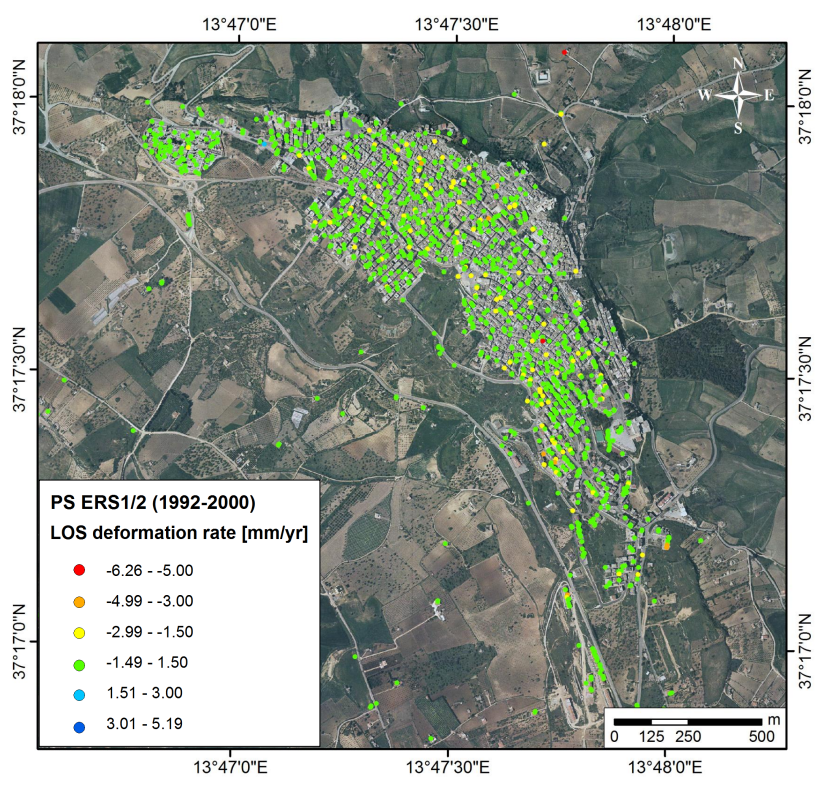

Fig. 6. PS ground deformation rates in the town of Naro in 1992-2000, measured along the LOS of ERS1/2 satellites in descending acquisition mode (see also Fig. 5a). Negative deformation values indicate movement toward the satellite. Positive values indicate movement away from the satellite.

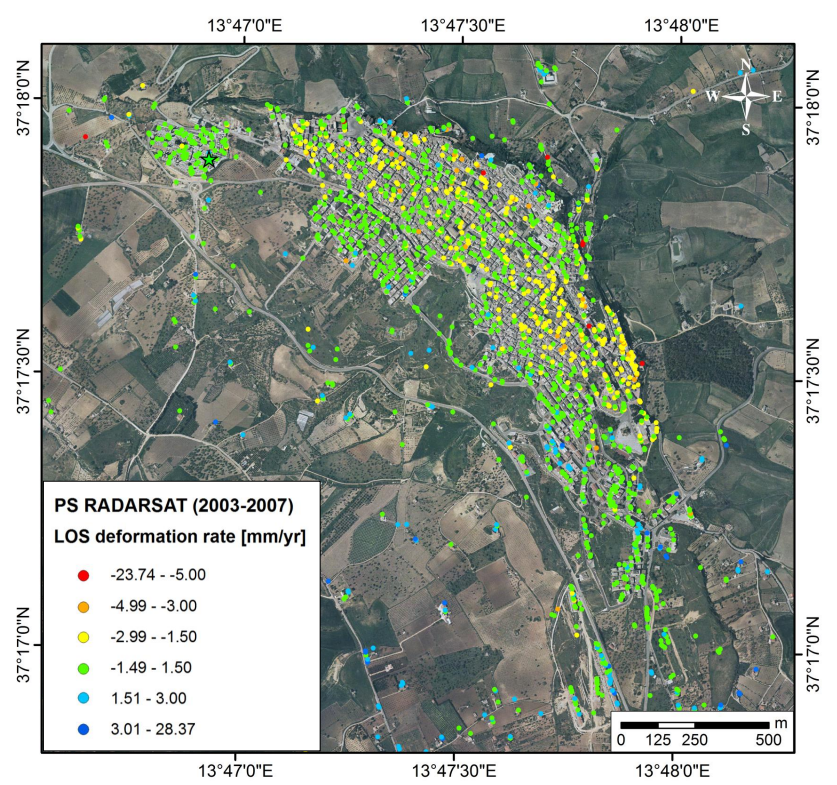

Fig. 7. PS ground deformation rates in the town of Naro in 2003-2007, measured along the LOS of RADARSAT-1 (Standard Beam, mode 3) satellite in ascending acquisition mode (see also Fig. 5b). Negative deformation values indicate movement toward the satellite; positive values indicate movement away from the satellite. The reference point location (green star) is also shown. a rapid motion (of about 5-10 $\mathrm{mm}$ away from the sensor; lower than $\lambda / 4$, i.e. $14 \mathrm{~mm}$ ) or an acceleration (temporary or permanent) of the deformation rate (up to $40-50 \mathrm{~mm} \mathrm{yr}^{-1}$ ) between January and March 2005. Furthermore, some PS underwent moderate deformation precursors starting from September 2004 (Fig. 8).

These single observations on these few targets suggested performing an advanced analysis of all the PS time series and, in particular, carrying out:

- an under-sampling in three different time intervals (i.e. before, during and after the 2005 event);

- a time series classification (i.e. affected or unaffected by the 2005 event).

In order to understand the differences between the mean annual rates of deformation, the interval 2003-2007 was divided into 3 subsamples (cutting the time period on September 2004 and just after 4 February 2005) and, for each of them, a new mean deformation rate was calculated using a simple linear regression on ground deformation data (Figs. 1 and 9). The coefficients of determination of the linear regression (i.e. $R^{2}$ ), calculated for each temporal subsample and each PS time series, range between 0.1 and 0.25 for a significant percentage of the targets (e.g. $61 \%$ of the PS are characterized by $R^{2}$ lower than 0.25 in the interval September 2004 - March 2005), highlighting a significant variability of deformation data with respect to the linear functions used to perform the temporal under-sampling (i.e. high sum of squared residuals from the recalculated rates). Nevertheless, a qualitative analysis allowed us to distinguish three slightly different deformation behaviours in 2003-2007. Prior to the 2005 event, variable deformation rates were measured all over the town (Fig. 9a) while in the second subsample of data, from September 2004 up to March 2005, a very high acceleration was recorded (maximum total displacement of $15-20 \mathrm{~mm}$, corresponding to $40-50 \mathrm{~mm} \mathrm{yr}^{-1}$, away or toward the satellite, Fig. 9b). Following the event of February 2005, the motion rate of many radar targets decreased up to $1 \mathrm{~mm} \mathrm{yr}^{-1}$, suggesting the stabilization of nearly the whole area (Fig. 9c). Most of these progressively stabilizing targets are located in the southeastern part of the town and only few of them are located in the historic area (Vanelle St.).

Since different deformational behaviours in 2005 were also detected and measured through the observation of several PS time series, a simple approach to classify these deformational patterns was also used for Naro. Here, for RADARSAT data the affected/unaffected target classification described in the Sect. 2.2 (Figs. 2, 10 and 11) was employed. Even if the recognition of the displacement pattern was performed for most of the targets, some PS time series did not show a clearly distinguishable deformational pattern, consequently they were not classified. 

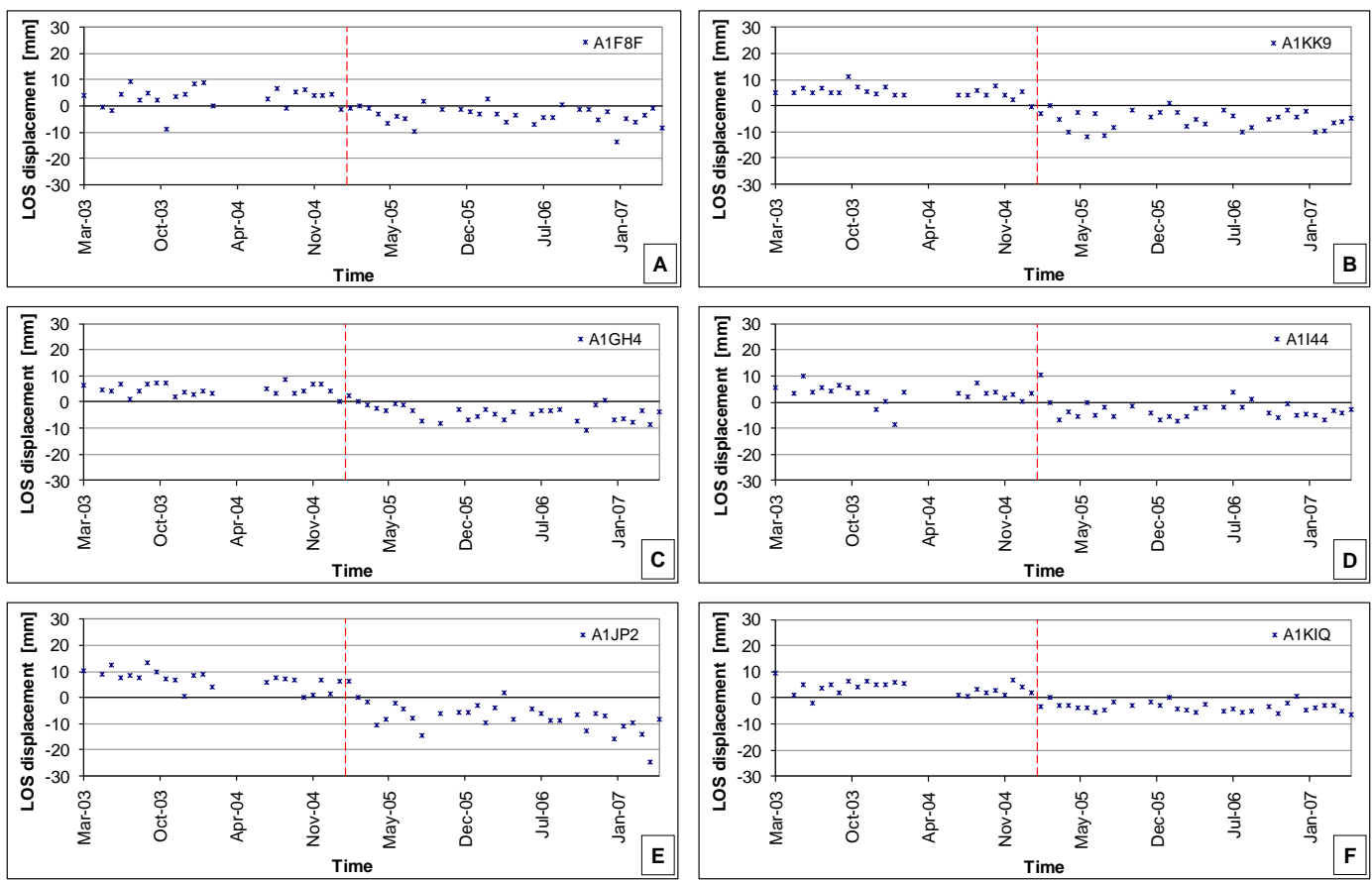

Fig. 8. Examples of LOS deformation time series (RADARSAT-1 data, 2003-2007) for the buildings of Vanelle St. and the central area of the town of Naro. Some rapid displacements (about $5-10 \mathrm{~mm}$ ) and temporary or permanent accelerations of the deformation rates (up to $40-50 \mathrm{~mm} \mathrm{yr}^{-1}$ ), can be detected starting from the end of 2004 and up till March 2005. These movements are connected with the fracture reactivation of February 2005 (red dashed line).

This post-processing analysis of PS time series was performed for Naro through a manual recognition and classification of the deformational behaviour of each RADARSAT PS (i.e. plotting all the 2003-2007 time series). However, we are now using the outcomes of this manual and time-consuming classification as a validation input for some semi-automatic algorithms that we are currently developing and experimenting with. These algorithms aim to identify anomalies, accelerations and/or variations registered inside PS time series.

As shown in Fig. 11, thanks to the identification of the urban sectors that moved during the event of 2005, the classification of time series showed that the affected area was larger than the one detected by in situ observations (historic and southeastern areas). Indeed, it included other parts of the town, such as the northeastern and the eastern areas (Fig. 11). Starting from this PS classification, we identified and mapped different sectors of the town that include only radar targets characterized by similar deformation behaviour (i.e. affected or unaffected targets). Consequently, 9 homogeneous areas - generally stretched from NW to SE - were recognized and differentiated over the whole urban area (Fig. 12): areas 1-6 as unaffected by the 2005 event and areas $7-9$ as affected.

\section{Discussion}

The outcomes from the PS time series analysis carried out for Naro were compared and integrated with results of conventional in situ investigations, such as structural, geomorphologic and damage field surveys, in order to identify any correlation between satellite measures and ground truth and to clarify causes and typology of the ground instability affecting this area.

\subsection{PSI time series vs. building fractures}

During some field surveys carried out in 2006 and 2007, structural data concerning many fractures opened in 2005 in the buildings of Vanelle St. were collected. For each, the horizontal and vertical components of relative displacement were detected and measured, identifying two homologous points - easily distinguishable - on its opposite edges (Fig. 13). Based on these displacement components, together with the spatial orientation of the buildings in which the fractures were located, we estimated the orientation parameters of the recorded displacement vectors. Subsequently, using the orientation characteristics of RADARSAT-1 LOS in the ascending configuration, we calculated - for each fracture - the percentage of the displacement vector that the satellite was able to detect. This quantity corresponds to the cosine of the angle between 

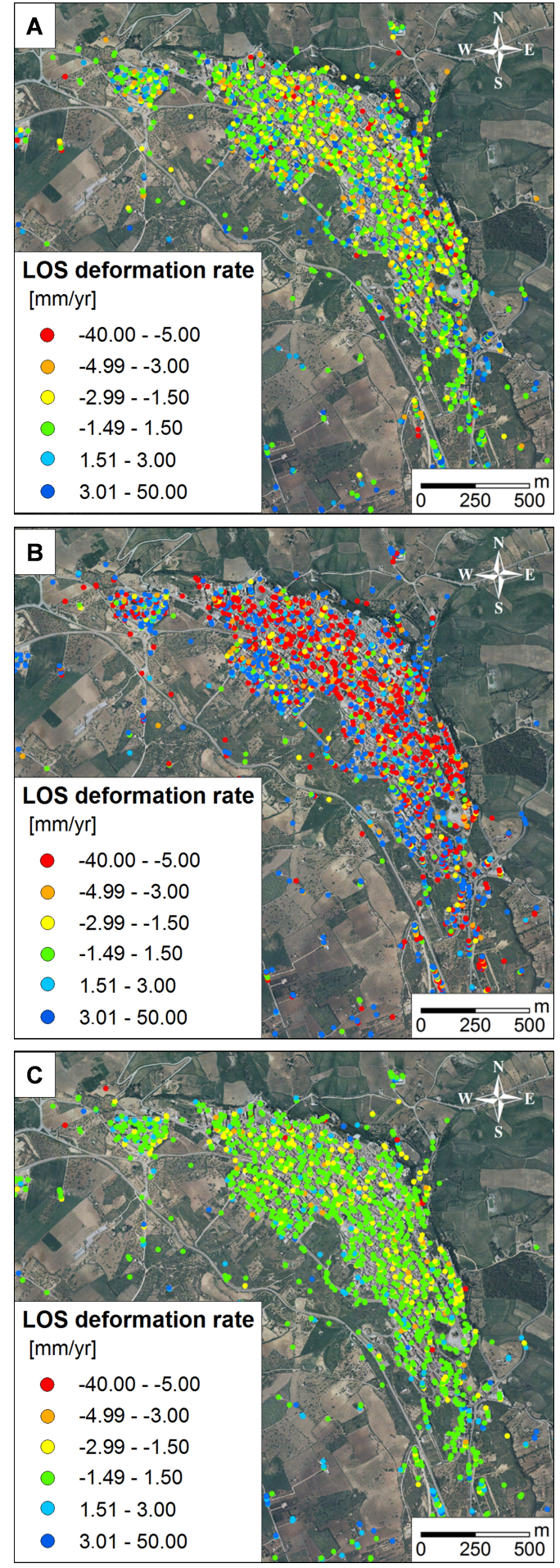

Fig. 9. Sub-sampling of Naro deformation time series into three different intervals: (A) (March 2003-September 2004), variable deformation rates; (B) (September 2004-March 2005), acceleration; (C) (March 2005-May 2007), stabilization. PS deformation rates are measured along the LOS of RADARSAT-1 satellite in ascending mode (see also Fig. 5b). Negative deformation values indicate movement toward the satellite; positive values indicate movement away from the satellite. the $\boldsymbol{L O S}$ and the displacement $(\boldsymbol{S})$ vectors, as derived by performing the dot product of the two respective unit vectors (Fig. 13). The mean deformation rates measured with the interferometric analysis were then used to calculate the corresponding values projected on the real movement direction (as collected during the field survey). The results of this analysis showed that only a small percentage (10-30\%) of these displacements was detected by RADARSAT LOS, therefore, the deformation rates occurring between 2003 and 2007 were much higher than those measured by means of the PS technique, just as expected (Crosetto et al., 2008, 2010; Raucoules et al., 2009).

The previous evidence is due not only to the LOS nature of PSI measures (i.e. PSI deformation measures are the projection of actual ones along the satellite LOS) but also to the linear model used during the PSI processing. The time series, de facto, mainly reflect the linear trend of deformation, while the non-linear part is rather small (usually much smaller than the actual one) and the rest of it is hidden in the wrapped part of the interferometric phases.

Considering also the PSI aliasing effect (see Sect. 2.2) and the amount of ground deformation measured in the building fractures (up to $6-7 \mathrm{~cm}$ ), it is reasonably possible that the actual deformation opened in the urban structures produced a phase-unwrapping misunderstanding during the PSI processing due to the overcoming of the $\lambda / 4$ displacement (i.e. $14 \mathrm{~mm}$ for C-band data). Thus, the rapid displacement measured by PSI data and registered inside the time series between January and March 2005 (about $5-10 \mathrm{~mm}$ ) probably reflects a value aliased from the one that occurred (error of two phase cycles, i.e. $\lambda, 56 \mathrm{~mm}$ ). This hypothesis agrees with the observations from the fracture surveys carried out after February 2005 in most of the damaged sectors of the town; unfortunately, no further information that could have confirmed the registration of aliased deformation in 2005 has been obtained from recent geological surveys.

\subsection{PSI time series vs. structural damage}

PS 1992-2000 and 2003-2007 deformation measures were also compared with three different levels of structural damage (high, medium and low) recorded in the buildings of the historic and southeastern areas of the town, identified and mapped in the framework of the RiscMass project (Basile and Cocina, 2006). For each building, a data sheet was created and filled in with the following information: observed damage, PS distribution, mean ground deformation rates and PS time series (Fig. 14). The analysis showed a strong correspondence between the structural damages of the buildings and PS deformation rates and time series: many PS affected by the event of February 2005 (i.e. affected targets, classes T and P; Fig. 2) were identified over the buildings classified with high or medium damage level (Fig. 14). 

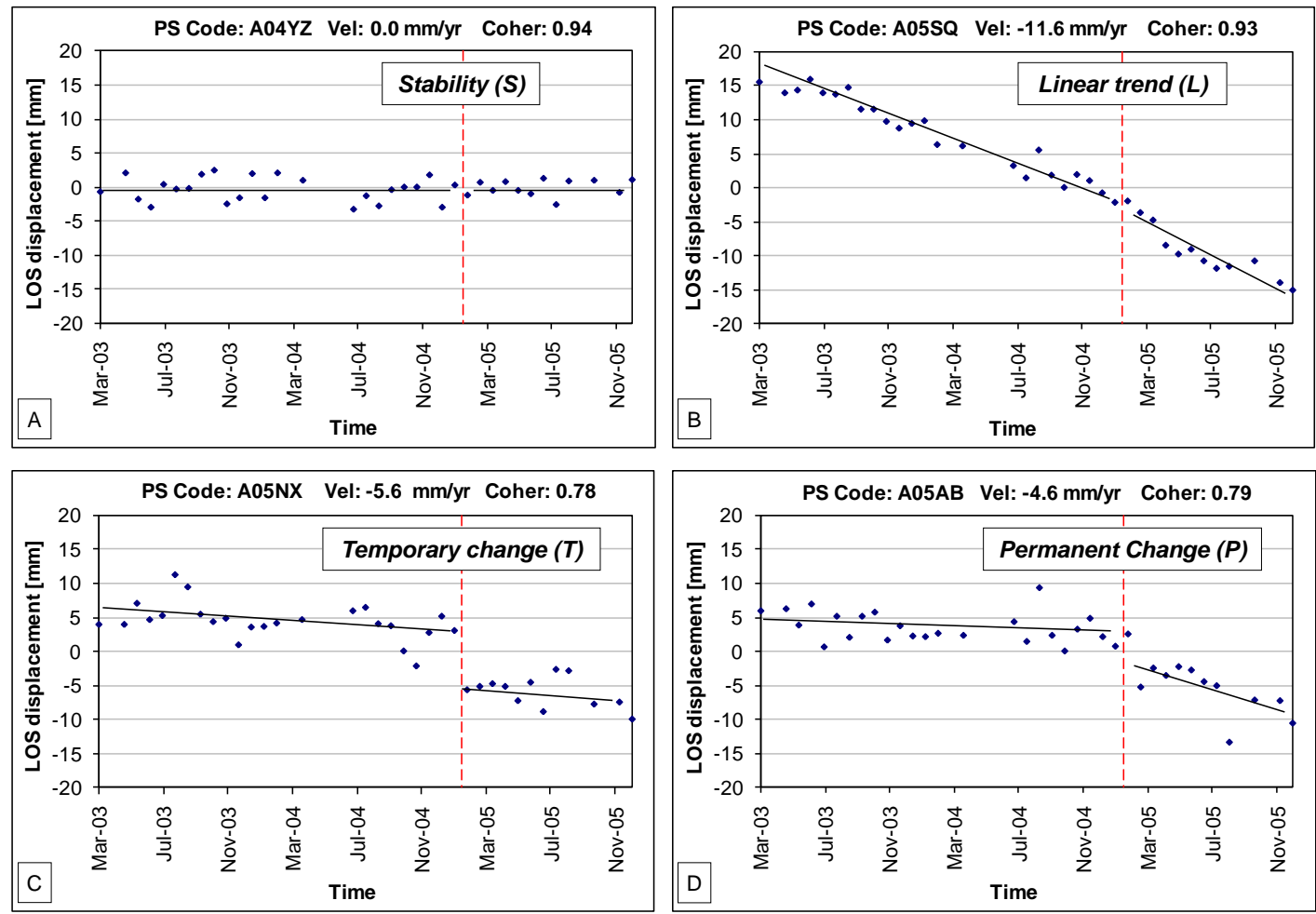

Fig. 10. Examples of RADARSAT PS time series unaffected (A, class S; B, class L) and affected (C, class T; D, class P) by the 2005 event (red dashed line). PS code, average deformation rate (Vel.) in 2003-2007 and coherence (Coher.) are also shown for each PS.

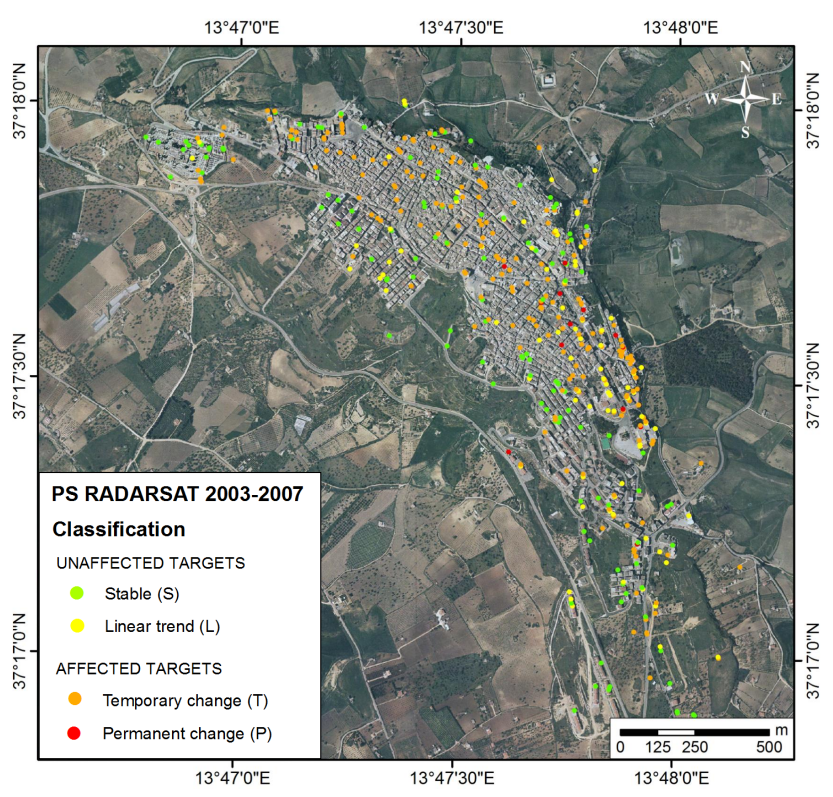

Fig. 11. Classification of RADARSAT PS time series according to the different behaviours with respect to the 2005 event, as defined in Fig. 2: unaffected (classes $\mathrm{S}$ and L) and affected targets (classes $\mathrm{T}$ and $\mathrm{P})$.

\subsection{PSI time series vs. geomorphologic evidence}

The result of the analysis of PS time series and ground deformation patterns was finally compared with the geomorphologic setting of the town (Fig. 12), highlighting a strong correlation between the presence of different geomorphologic scarps in the calcarenite-clayey slope and the sudden change of PS 2003-2007 deformation behaviour. PS showed different motion patterns upstream and downstream these main scarps, confirming the presence of subsurface faults that triggered the ground deformation of 2005 and consequently inducing us to exclude the hypothesis of a landslide process in Naro. As stated before, these scarps are reasonably connected to the geological evolution of the Gela Nappe: its $\mathrm{N}-\mathrm{S}$ motion induces SE-NW local faulting in the whole Caltanissetta basin and, probably, the opening and periodical reactivation of many SE-NW fractures in the calcarenite sediments of Naro hill and, as a consequence, in buildings and roads of its urban area.

\subsection{Final interpretation of ground instability}

The integration of further conventional geological investigations and field surveys with InSAR radar-interpretation finally revealed valuable evidence of active tectonic structures affecting, at local scale, the urban area of Naro. 


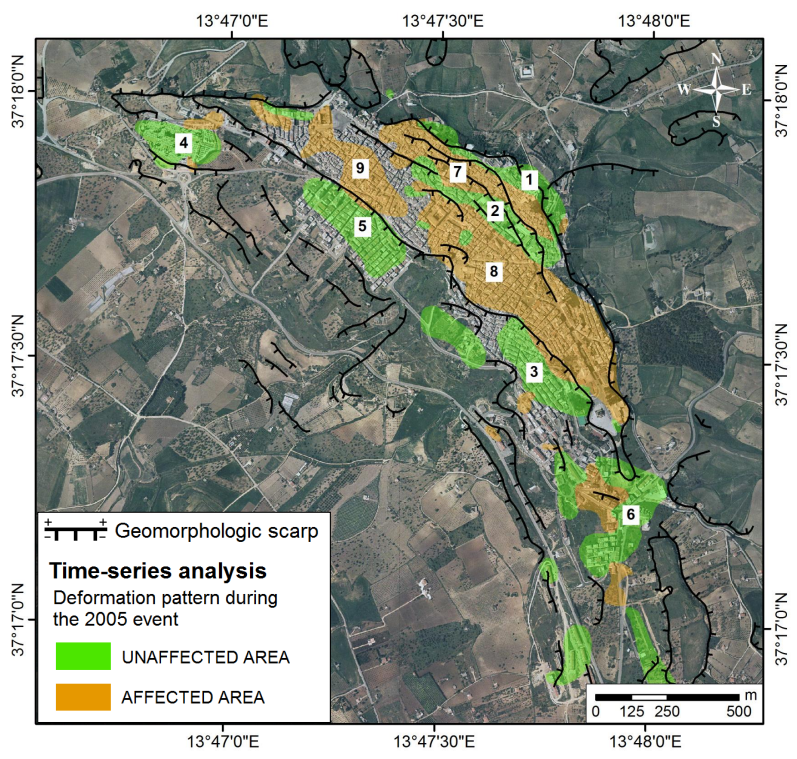

Fig. 12. Final result of the PS time series analysis and classification for Naro: identification and mapping of areas registering a homogeneous deformation pattern during the event that occurred on 4 February 2005: areas 1-6, unaffected by the event, and areas 7-9, affected. Geomorphologic scarps are overlapped on the deformation pattern map.

This evidence about the local geological setting of the town reflect the regional background of Caltanissetta basin in central-southern Sicily, characterized by active tectonic forces related to the underlying thrust structures of the frontal part of the Apennine-Maghrebian chain, in this area, the Gela Nappe (Grasso et al., 1995; Lickorish et al., 1999). According to this geological interpretation of ground instability in Naro, scarps and steep slopes detected and mapped inside the urban area (Figs. 12 and 15) may be the surface evidence of deep-seated tectonic structures.

The analysis of the regional seismicity of Sicily showed that the area of Naro is characterized by the lowest level of seismicity of the whole region (Delibera Regione Siciliana, n. 408, 19/12/2003). This observation is also consistent with the outcomes from the historical records and instrumental measurements of seismicity. These studies did not show a correlation between the last reactivations of ground instability in Naro and the occurrence of earthquakes in the whole area of Agrigento and southern Sicily (Boschi et al., 1997; Azzaro et al., 2000; INGV, 2004; Lavecchia et al., 2007). However, even if no seismic events were recorded in the whole area of Agrigento-Canicatti-Licata, the seismic available data do not allow us to absolutely correlate the 2005 event with an aseismic slip or, alternatively but less probably, the incompleteness of the historical catalogues or the low frequency of the seismic events.

Assuming the hypothesis of aseismic slip as the best explanation of ground instability in Naro, some remarks about the dislocation of the subsurface tectonic structures need to be pointed out. Displacements recorded by PS and during field investigations (e.g. fracture displacement) cannot be considered as the exact amount of dislocation underwent by the subsurface faults. The deformation recorded on the ground is, in fact, the result of a complex propagation of tensile and compressive stresses, coming from the subsurface faulting and transferred to surface urban structures. The propagation and attenuation (or increase) of deformation are driven by several components: (i) rheological characteristics of the geological lithologies of the area; (ii) position of the buildings with respect to the fault; (iii) structural vulnerability of the building (typology and maintenance status of the foundations, construction materials and geometry). Thus, unless we assume a rigid displacement model for the building together with the subsurface fault, both field and satellite measures do not exactly correspond to the actual fault displacement. However, the magnitude of such measures (up to few $\mathrm{cm} \mathrm{yr}^{-1}$ ) is not in contradiction with the temporal patterns of a geological process of aseismic slip.

The outcomes of the InSAR and in situ integrated analysis were successfully exploited for Naro by the regional civil protection authorities as a valuable and efficient support for mapping hazard and the identification of appropriate mitigation measures. Due to the peculiar causes of Naro's geological risk (connected to periodical reactivation of SE-NW faults and consequently, the differential ground deformation affecting the calcarenite-clayey hill on which the town is built), high hazard areas were located on or close to the main fractures, historically known and periodically recurring (Vanelle St.). In these areas, geology and tectonics do not allow structural stabilization. The only suitable mitigation measures, carried out by the civil protection authorities, were the relocation of buildings and elements at risk to safer areas, the demolition of the most damaged structures, the maintenance and consolidation of the less damaged ones, and the prohibition of new constructions. However, for the areas where the fractures are isolated, discontinuous and not directly associated with the ground deformation in the historic area of the town (e.g. Gesù Maria St. and areas 8-9 in Fig. 12), a better knowledge of geological conditions and the periodic structural monitoring of buildings and fractures are considered the most sustainable and effective countermeasures to reduce risk for the population.

\subsection{Future perspectives of the new post-processing methodology}

The application of the new post-processing approaches to the case study of Naro showed the possibility of extracting deformation components different from the expected linear trend (as long as they are limited) from PSI time series, even if a linear deformation model is used during the processing. 

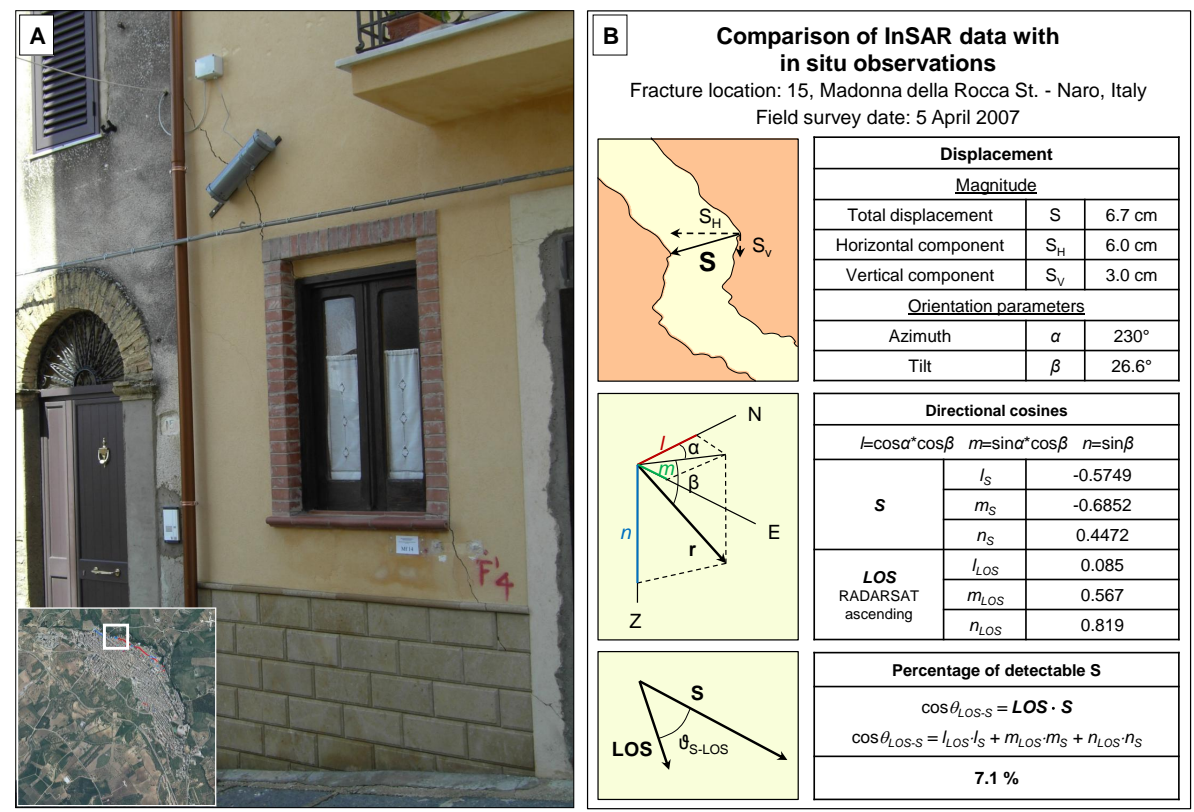

Fig. 13. Example of comparison of LOS orientation with the deformation direction detected during field surveys. (A): Location (inset) and photo of measured fracture (photos taken on 5 April 2007). (B): 3-D orientation characteristics of real ground displacement (S) and RADARSAT (Standard Beam, ascending mode) LOS, and evaluation of LOS-detectable ground displacement [\%]. LOS and $S$ vectors are identified by azimuth $(\alpha)$, tilt $(\beta)$ and directional cosines $(l, m$ and $n$, respectively, in the $\mathrm{N}$, E and vertical or $\mathrm{Z}$ direction).
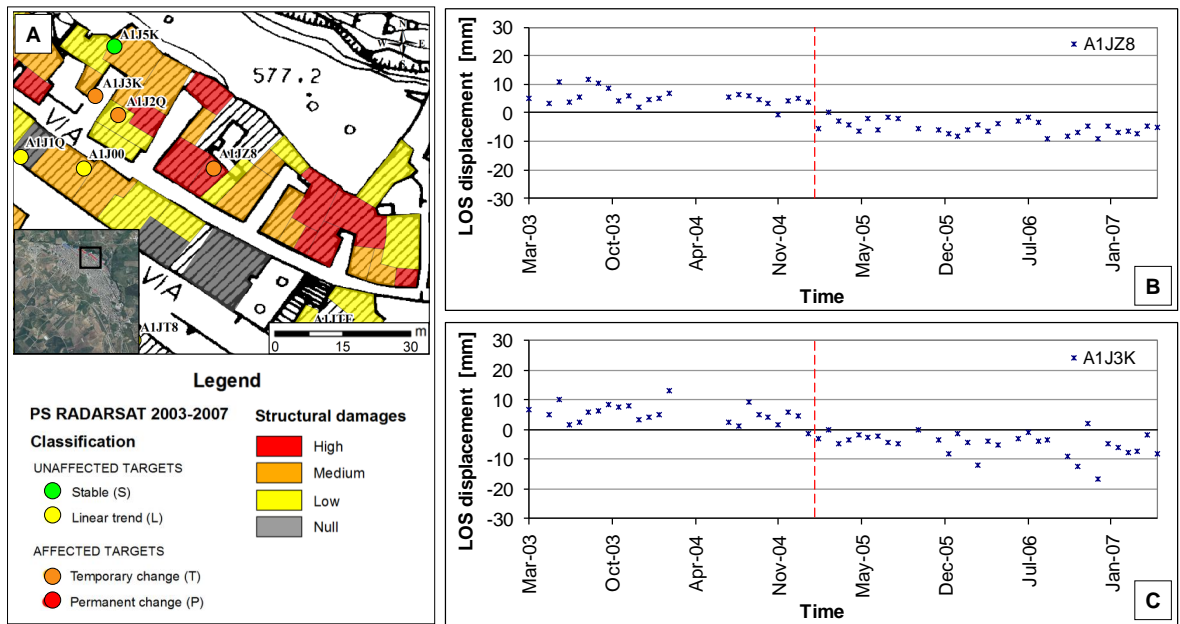

Fig. 14. (A): Comparison of PS deformation behaviours with structural damage mapped on the buildings in the framework of RiscMass project (Basile and Cocina, 2006), overlapped on a 1:2000 topographic map: inset on some buildings located in Vanelle St. (historic area). B, C: Example of PS time series for buildings affected by structural damages of high or medium level. Their trends underwent some temporary changes (T pattern, see Fig. 2) that are probably related to the ground displacements occurred on 4 February 2005 (red dashed line). PS displacements are measured along RADARSAT-1 (2003-2007) LOS in ascending mode.

Obviously, the choice of the deformation model of phase variation and the processing strategies have key roles during the PSI analysis and they are strictly dependent on the application at hand. When a priori information about the geological process affecting the investigated area is available, the analysis should be calibrated to the real physical trend of the geological process (Kim et al., 2010).
In any case, it is always worth analyzing the PSI temporal series of ground deformation in detail and not only the average trends, since the history of displacements, acquisition by acquisition, may give us further information about the spatial and temporal behaviour of the investigated process. We are now developing and experimenting some algorithms for the semi-automatic analysis of PSI time 


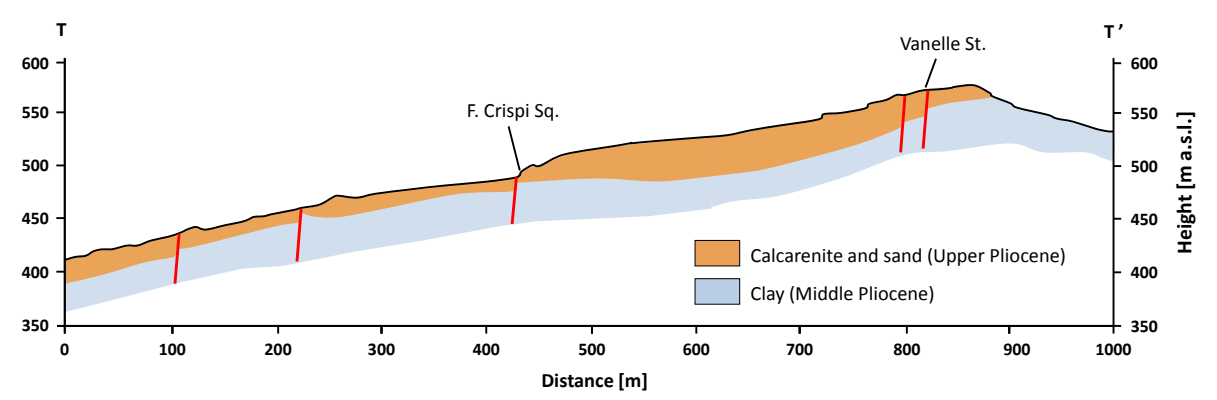

Fig. 15. Simplified cross section T-T'. (Fig. 3), showing the geological (lithological) setting of Naro and the hypothesized distribution of the main surface faults (red lines) derived from recent geological investigations (modified from Basile, 2007).

series and for the detection of temporal changes of their deformation patterns. The final purpose of these algorithms is not only the automation of advanced PS classifications (e.g. Naro case study) but also the definition of a future early warning system for geological hazards, based on the identification of potential deviations from the expected deformation trends and the consequent analysis of future risk scenarios.

We are now working on the calibration of these models using the outcomes of manual and laborious PS classifications and analyses, as we performed for Naro. Since these kind of algorithms are usually site-specific (i.e. they depend on the particular application at hand), a single change detection model cannot obviously be defined and used for all the PSI analyses.

In general, good temporal sampling and spatial resolution of satellite SAR data are the primary requirements for the implementation of post-processing PSI time series analyses. However, these requirements may often be compromised by the high cost of large SAR data stacks.

\section{Conclusions}

The new approach for the interpretation of PSI time series allowed the study of the spatial and temporal characteristics of the ground instability that affected Naro in 2005, highlighting the capabilities of this advanced analysis as a valuable tool for the study of surface evidence of geological processes and confirming the potentials of the "back monitoring" approach for the study of historical displacements.

The urbanization provided a good distribution of radar targets in the area of Naro, allowing the identification of the ground deformation which occurred in 2005 and their spatial distribution. According to InSAR measures, the displacements of February 2005 did not happen suddenly but were preceded by deformation precursors since September 2004. Moreover, the analysis showed that the affected area was larger than the one detected by in situ structural surveys and it included the northeastern and eastern parts of the town as well. The integration of radar satellite data together with in situ geological, geomorphologic and geostructural investigations (carried out in collaboration with the Regional Civil Protection Department of Sicily), finally induced us to exclude the hypothesis of a landslide process in Naro. Rather they confirmed that the 2005 event was related to tectonics (in accordance also with the general tectonic background of Caltanissetta basin). The outcomes of this analysis for Naro consequently turned out to be very helpful and useful for civil protection authorities, as a supporting tool for hazard mapping and for the identification of the appropriate mitigation measures.

Today, the improved acquisition frequency achievable through new high-resolution SAR satellite sensors, such as TerraSAR-X and COSMO-SkyMed constellation (3-4 acquisitions per month; up to 1 image per day), encourages the planning and design of a "near real-time" satellite monitoring and early warning service for geological risks. This opens up new opportunities and perspectives for the operational use of advanced InSAR techniques in civil protection practices. Thus, advantages and possible add-ons offered by the use of automatic or semi-automatic analyses of PSI time series and the consequent recognition of deviations from regular and expected trends are now becoming urgent and critical topics of discussion for the scientific community.

Acknowledgements. This work was performed within the framework of the Italian projects "SAR.net", funded by the Italian Civil Protection Department, and "Interpretazione di dati telerilevati per lo studio delle condizioni di dissesto nel Comune di Agrigento e nel centro abitato di Naro", funded by the Regional Civil Protection Department (DRPC), Sicily. The authors would like to thank Giuseppe Basile and all the DRPC staff, for having supported and collaborated during the whole analysis. We are also grateful to TeleRilevamento Europa (TRE), Italy, for having processed ERS and RADARSAT data with the PSInSAR technique and for their fruitful collaboration. Moreover, we gratefully acknowledge Patrizia Musina (University of Firenze, Italy) and Sean Peter Ahearn (University of Miami, USA) for their helpful and careful language reviews.

Edited by: R. Lasaponara

Reviewed by: J. Vlcko, C. Meisina, and another anonymous referee 


\section{References}

Azzaro, R., Barbano, M. S., Antichi, B., and Rigano, R.: Macroseismic catalogne of Mt Etna earthquakes from 1832 to 1998, Acta Vulcanologica, 12 (1), 3-36, 2000.

Basile, G.: Relazione finale sulla campagna di indagini geognostiche a Naro (Ag), Ordinanza del P.C.M. no. 3450/2005, 180 pp., 2007.

Basile, G. and Cocina, S.: Progetto RiscMass - Metodologie per la gestione del rischio frana e dei movimenti del suolo con scenari di politica assicurativa - Il caso di Naro (Ag), Rapporto finale, Programma Comunitario Interreg IIIb MedOcc, 51 pp., 2006.

Berardino, P., Fornaro, G., Lanari, R., and Sansosti, E.: A new algorithm for surface deformation monitoring based on Small Baseline Differential SAR Interferograms, IEEE T. Geosci. Remote, 40 (11), 2375-2383, 2002.

Boschi, E., Guidoboni, E., Ferrari, G., Valensise, G., and Gasperini, P.: Catalogo dei Forti Terremoti in Italia dal 461 a.C. al 1990, ING e SGA, Bologna, 644 pp., 1997.

Bovenga, F., Nutricato, R., Refice, A., and Wasowski, J.: Application of multi-temporal differential interferometry to slope instability detection in urban/peri-urban areas, Eng. Geol., 88, 219-240, 2006.

Browitt, C., Walker, A., Farina, P., Devleeschouwer, X., Tragheim, D., and Aktar, M.: Terra not so firma, Geoscientist, Geol. Soc. London, 17 (6), 18-22, 2007.

Bürgmann, R., Hilley, G. E., and Ferretti, A.: Resolving vertical tectonics in the San Francisco Bay Area from Permanent Scatterer InSAR and GPS Analysis, Geology, 34, 221-224, 2006.

Canuti, P., Casagli, N., Farina, P., Ferretti, A., Marks, F., and Menduni, G.: Land subsidence in the Arno river basin studied through SAR Interferometry, in: Proceedings of SISOLS 2005, 7th International Symposium on Land Subsidence, Shanghai, China, 23-28 October 2005, 1, 407-416, 2005.

Casagli, N., Cigna, F., Del Conte, S., and Liguori, V.: Nuove tecnologie radar per il monitoraggio delle deformazioni superficiali del terreno: casi di studio in Sicilia, Geologi di Sicilia, Anno XVII (3), 17-27, 2009.

Cigna, F., Bianchini, S., Righini, G., Proietti, C., and Casagli, N.: Updating landslide inventory maps in mountain areas by means of Persistent Scatterer Interferometry (PSI) and photo-interpretation: Central Calabria (Italy) case study, in: Mountain Risks: Bringing Science to Society (572 pp.), edited by: Malet, J.-P., Glade, T., and Casagli, N., Proc. of the International Conference, CERG Editions, Florence, Italy, 24-26 November 2010, 3-9, 2010a.

Cigna, F., Del Ventisette, C., Liguori, V., and Casagli, N.: InSAR time-series analysis for management and mitigation of geological risk in urban area, in: Proceedings of IGARSS 2010, 30th IEEE International Geoscience and Remote Sensing Symposium, Honolulu, Hawaii, USA, 25-30 July 2010, 1924-1927, 2010b.

Colesanti, C. and Wasowski, J.: Investigating landslides with space-borne Synthetic Aperture Radar (SAR) Interferometry, Eng. Geol., 88, 173-199, 2006.

Colesanti, C., Ferretti, A., Prati, C., and Rocca, F.: Monitoring landslides and tectonic motions with the Permanent Scatterers Technique, Eng. Geol., 68, 3-14, 2003.
Corsini, A., Farina, P., Antonello, G., Barbieri, M., Casagli, N., Coren, F., Guerri, L., Ronchetti, F., Sterzai, P., and Tarchi, D.: Space-borne and ground-based SAR interferometry as tools for landslide hazard management in civil protection, Int. J. Remote Sens., 27 (12), 2351-2369, 2006.

Costantini, M., Iodice, A., Magnapane, L., and Pietranera L.: Monitoring terrain movements by means of sparse SAR differential interferometric measurements, in: Proceedings of IGARSS 2000, 20th IEEE International Geoscience and Remote Sensing Symposium, Honolulu, Hawaii, USA, 24-28 July 2000, 3225-3227, 2000.

Crosetto, M., Crippa, B., Biescas, E., Monserrat, O., and Agudo, M.: State-of-the-art of land deformation monitoring using differential SAR Interferometry, in: Proceedings of the ISPRS Workshop 2005, High Resolution Earth Imaging for Geospatial Information, Hannover, Germany, 17-20 May 2005, XXXVI, Part 1/w3, 2005.

Crosetto, M., Biescas, E., Duro, J., Closa, J., and Arnaud, A.: Quality assessment of advanced interferometric products based on time series of ERS and Envisat SAR data, Photogramm. Eng. Rem. S., 74 (4), 443-450, 2008.

Crosetto, M., Monserrat, O., Iglesias, R., and Crippa, B.: Persistent Scatterer Interferometry: potential, limits and initial C- and X-band comparison, Photogramm. Eng. Rem. S., 76 (9), 1061-1069, 2010.

Dixon, T. H., Amelung, F., Ferretti, A., Novali, F., Rocca, F., Dokka, R., Sella, G., Kim, S. W., Wdowinski, S., and Whitman, D.: Subsidence and flooding in New Orleans - A subsidence map of the city offers insight into the failure of the levees during Hurricane Katrina, Nature, 441, 587-588, 2006.

Farina, P., Colombo, D., Fumagalli, A., Marks, F., and Moretti, S.: Permanent Scatterers for landslide investigations: outcomes from the ESA-SLAM project, Eng. Geol., 88, 200-217, 2006.

Farina, P., Casagli, N., and Ferretti, A.: Radar-interpretation of InSAR measurements for landslide investigations in civil protection practices, in: Proceedings of the 1st North American Landslide Conference, Vail, Colorado, 3-8 June 2007, 272-283, 2008.

Ferretti, A., Prati, C., and Rocca, F.: Non-linear subsidence rate estimation using Permanent Scatterers in Differential SAR Interferometry, IEEE T. Geosci. Remote, 38 (5), 2202-2212, 2000.

Ferretti, A., Prati, C., and Rocca, F.: Permanent Scatterers in SAR interferometry, IEEE T. Geosci. Remote, 39 (1), 8-20, 2001.

Ferretti, A., Prati, C., Rocca, F., Casagli, N., Farina, P., and Young, B.: Permanent Scatterers technology: a powerful state of the art tool for historic and future monitoring of landslides and other terrain instability phenomena, in: Proceedings of the 2005 International Conference on Landslide Risk Management, A.A. Balkema, Vancouver, Canada, 31 May-1 June 2005, CD-Rom, 2005.

Fruneau, B., Achache, J., and Delancourt, C.: Observation and modelling of the Saint- Etienne-de-Tinee landslide using SAR Interferometry, Tectonophysics, 265, 181-190, 1996.

Ghisetti, F. C., Gorman, A. R., Grasso, M., and Vezzani, L.: Imprint of foreland structure on the deformation of a thrust sheet: The Plio-Pleistocene Gela Nappe (southern Sicily, Italy), Tectonics, 28 (4), TC4015, 2009. 
Goldstein, R. M., Engelhardt, H., Kamb, B., and Frolich, R. M.: Satellite radar interferometry for monitoring ice sheet motion: application to an Antarctic ice stream, Science, 262 (5139), 1525-1530, 1993.

Grasso, M. and La Manna, F.: Lineamenti stratigrafici e strutturali del fronte della Falda di Gela affiorante a NW del Plateau Ibleo (Sicilia sud-orientale), Geologica Romana, 29, 55-72, 1990.

Grasso, M., Miuccio, G., Maniscalco, R., Garofano, P., La Manna, F., and Stamilia, R.: Plio-Pleistocene structural evolution of the Hyblean Plateau and the Maghrebian foredeep, SE Sicily. Implications for the deformational history of the Gela Nappe, Annales Tectonicae, 9 (1-2), 7-21, 1995.

Greif, V. and Vlcko, J.: Monitoring of post-failure landslide deformation by the PS-InSAR technique at Lubietova in Central Slovakia, Environmental Earth Sciences, doi:10.1007/s12665011-0951-x, 2011.

Hanssen, R. F.: Satellite radar interferometry for deformation monitoring: a priori assessment of feasibility and accuracy, Int. J. Appl. Earth Obs., 6, 253-260, 2005.

Herrera, G., Davalillo, J. C., Mulas, J., Cooksley, G., Monserrat, O., and Pancioli, V.: Mapping and monitoring geomorphological processes in mountainous areas using PSI data: Central Pyrenees case study, Nat. Hazards Earth Syst. Sci., 9, 1587-1598, doi:10.5194/nhess-9-1587-2009, 2009.

Hilley, G. E., Bürgmann, R., Ferretti, A., Novali, F., and Rocca, F.: Dynamics of slow-moving landslides from Permanent Scatterer analysis, Science, 304 (5679), 1952-1955, 2004.

Hooper, A., Zebker, H., Segall, P., and Kampes, B.: A new method for measuring deformation on volcanoes and other natural terrains using InSAR persistent scatterers, Geophys. Res. Lett., 31 (23), L23611, doi:10.1029/2004GL021737, 2004.

INGV: http://emidius.mi.ingv.it/CPTI04/, last access: 26 October 2010, 2004.

Kim, S. W., Wdowinski, S., Amelung, F., Dixon, T. H., Won, S. J., and Kim, J. W.: Measurements and predictions of subsidence induced by soil consolidation using permanent scatterer InSAR and hyperbolic model, Geophys. Res. Lett., 37, L05304, doi:10.1029/2009GL041644, 2010.

Kimura, H. and Yamaguchi, Y.: Detection of landslide areas using satellite radar Interferometry, Photogramm. Eng. Rem. S., 66 (3), 337-344, 2000.

Lanari, R., Berardino, P., Borgström, S., Del Gaudio, C., De Martino, P., Fornaro, G., Guarino, S., Ricciardi, G. P., Sansosti, E., and Lundgren, P.: The use of IFSAR and classical geodetic techniques for caldera unrest episodes: application to the Campi Flegrei uplift event of 2000, J. Volcanol. Geoth. Res., 133, 247-260, 2004.

Lavecchia, G., Ferrarini, F., De Nardis, R., Visini, F., and Barbano, M. S.: Active thrusting as a possible seismogenic source in Sicily (Southern Italy): Some insights from integrated structural-kinematic and seismological data, Tectonophysics, 445, 145-167, 2007.

Lentini, F., Carbone, S., and Guarnieri, P.: Collisional and postcollisional tectonics of the Appenninic-Maghrebian orogen (southern Italy), in: Post-collisional tectonics and magmatism in the Mediterranean region and Asia, Y. Dilek and S. Pavlides (Eds.), The Geological Society of America, Washington, 57-81, 2006.
Lickorish, W. H., Grasso, M., Butler, R. W. H., Argnani, A., and Maniscalco, R.: Structural style and regional tectonic setting of the "Gela Nappe" and frontal part of the Maghrebian thrust belt in Sicily, Tectonics, 18 (4), 655-668, 1999.

Massonnet, D. and Feigl, K. L.: Radar interferometry and its application to changes in the Earth's surface, Rev. Geophys., 36, 441-500, 1998.

Massonnet, D., Feigl, K. L., Rossi., M., and Adrangna, F.: Radar interferometric mapping of deformation in the year after the Landers Earthquake, Nature, 369, 227-230, 1994.

Mora, O., Mallorqui, J., and Broquetas, A.: Linear and non-linear terrain deformation maps from a reduced set of interferometric SAR images, IEEE T. Geosci. Remote, 41 (10), 2243-2253, 2003.

Musson, R. M. W., Haynes, M., and Ferretti, A.: Space-based tectonic modelling in subduction areas using PSInSAR, Seismol. Res. Lett., 26 (9), 1913-1926, 2004.

Osmanoglu, B., Dixon, T. H., Wdowinski, S., Cabral-Cano, E., and Jiang, Y.: Mexico City subsidence observed with Persistent Scatterer InSAR, Int. J. Appl. Earth Obs., 13 (1), 1-12, 2011.

Pancioli, V., Raetzo, H., Campolmi, T., and Casagli, N.: Terrafirma Landslide Services for Europe based on Space-borne InSAR Data, in: Proceedings of the First World Landslide Forum, Tokyo, Japan, 18-21 November 2008, 81-84, 2008.

Raucoules, D., Bourgine, B., De Michele, M., Le Cozanet, G., Closset, L., Bremmer, C., Veldkamp, H., Tragheim, D., Bateson, L., Crosetto, M., Agudo, M., and Engdahl, M.: Validation and Intercomparison of Persistent Scatterers Interferometry: PSIC4 project results, J. Appl. Geophys., 68 (3), 335-347, 2009.

Regio Ufficio Geologico: Brevi cenni relativi alla Carta Geologica dell'Isola di Sicilia, Carta Geologica d'Italia, Roma, 1885.

Righini, G., Del Ventisette, C., Costantini, M., Malvarosa, F., and Minati, F.: Space-borne SAR Analysis for Landslides Mapping in the Framework of the PREVIEW Project, in: Proceedings of the First World Landslide Forum, Tokyo, Japan, 18-21 November 2008, 505-506, 2008.

Rosen, P. A., Hensley, S., Joughin, I. R., Li, F. K., Madsen, S. N., Rodriguez, E., and Goldstein, R. M.: Synthetic aperture radar Interferometry, in: Proceedings of the IEEE, 88 (3), 333-382, 2000.

Salvi, S., Atzori, S., Tolomei, C., Allievi, J., Ferretti, A., Rocca, F., Prati, C., Stramondo, S., and Feuillet, N.: Inflation rate of the Colli Albani volcanic complex retrieved by the permanent scatterers SAR interferometry technique, Geophys. Res. Lett., 31 (21), L12606, doi:10.1029/2004GL020253, 2004.

Singhroy, V., Mattar, K., and Gray, L.: Landslide characterization in Canada using interferometric SAR and combined SAR and TM images, Adv. Space Res., 2, 465-476, 1998.

Stramondo, S., Bozzano, F., Marra, F., Wegmuller, U., Cinti, F. R., Moro, M., and Saroli, M.: Subsidence induced by urbanization in the city of Rome detected by advanced InSAR technique and geotechnical investigations, Remote Sens. Environ., 112, 31603172, 2008.

Teatini, P., Tosi, L., Strozzi, T., Carbognin, L., Wegmüller, U., and Rizzetto, F.: Mapping regional land displacements in the Venice coastland by an integrated monitoring system, Remote Sens. Environ., 98, 403-413, 2005. 
Tizzani, P., Berardino, P., Casu, F., Euillades, P., Manzo, M., Ricciardi, G. P., Zeni, G., and Lanari, R.: Surface deformation of Long Valley caldera and Mono Basin, California investigated with the SBAS-InSAR approach, Remote Sens. Environ., 108, 277-289, 2007.

Vilardo, G., Ventura, G., Terranova, C., Matano, F., and Nardò, S.: Ground deformation due to tectonic, hydrothermal, gravity, hydrogeological, and anthropic processes in the Campania Region (Southern Italy) from Permanent Scatterers Synthetic Aperture Radar Interferometry, Remote Sens. Environ., 113 (1), 197-212, 2009.
Werner, C., Wegmuller, U., Strozzi, T., and Wiesmann, A.: Interferometric Point Target Analysis for deformation mapping, in: Proceedings of IGARSS 2003, 23rd Int. Geosci. Remote. Se., Toulouse, France, 21-25 July 2003, 4362-4364, 2003. 